\title{
The Influence of National Culture on New Product Creativity
}

\author{
Bing Xu \\ California State University, Dominguez Hills \\ Yam Limbu \\ Montclair State University \\ Zhongming Ma \\ California State Polytechnic University \\ Meng Zhao \\ California State University, Dominguez Hills
}

\begin{abstract}
Extant national culture research in the field of new product creativity from an individual consumer's perspective has never been done by scholars. The author developed a framework to drive and inspire new product creativity research. By applying contagion theory and Hofstede's culture frame, this study fills the gap and investigates the moderating effect of national culture on the relationship between new product creativity (NPC) and consumers' purchase intention (PI) through different aspects. A set of propositions demonstrates the testable theory application of the conceptual model. New constructs and significant relationships in the new context advance new product theory, research and practice in the decision-making process. This research also contributes to culture research related to purchase behaviors.
\end{abstract}

Keywords: National Culture, New Product, New Product Creativity, Purchase Intention

\section{INTRODUCTION}

With the fast pace of globalization, creativity-based new product competition has interested many scholars in international marketing. Resource-based theory argues that firms should focus on resources that are valuable, rare, imperfectly imitable and supported by firms' ability (Kozlenkova, Samaha and Palmatier, 2014; Gao, Tate, Zhang, Chen and Liang, 2018). The technology-based competitive strategy model (Rhyne, Teagarden and Panhuyzen 2002) also suggests that fostering creativity is essential for valuable and imperfectly imitable resources in firms, and knowledge-based creation and the ability to utilize the created knowledge are the most important competitive advantages in new product competition. At the same time, literature (Ashill and Jobber, 2014; Lee and Wong, 2012; Navarro-García, ArenasGaitán and Rondán-Cataluña, 2014) has emphasized the influence of the external environment on business success in the international market. Researchers point out that intangible assets that link all 
assets to task and external environments are the most important sources of competitive advantage (Hall 1993; Rhyne, Teagarden and Panhuyzen 2002). Therefore, the integration of knowledge-based, creative new products into the external environment is worthy of investigation.

Firms' external environments in international markets include influential factors from both the home and host countries, including cultural diversities among countries (Rhyne, Teagarden and Panhuyzen 2002; Zaheer 1992). Researchers argue that congruence of environmental factors between home and host countries is critical for success in global competition (Cui,Walsh and Zou, 2014; Adler and Ghadar 1990; Milliman, Von Glinow and Nathan 1991). Therefore, adjusting strategies to be adaptive to host countries is important for a firm's successful competition in the international market.

Among all factors resulting in cross-nation distance, culture is among the "most oft-cited and empirically validated factors contributing to psychic distance" (Baylei and $\mathrm{Li}, 2015$ ). Thus, recognizing and utilizing national culture is itself a strategy for creative new-product diffusion and success. Meanwhile, research has indicated that national culture is particularly relevant to business success (Patti,

Mudambi, Navarra and Baglieri, 2016). Different national cultures, if closely recognized, can be transformed for insight on significant competitive advantages, including localizing global brands or disseminating creative new products in terms of foreign cultural values. A good example is Starbucks. Starbucks sells hot tea in China because tea is an essential part of Eastern food culture.

Of course, the premise of managing cultural values for product strategies is that we must acknowledge how cultural value influences marketing and new product development (NPD). Studies of national culture in marketing context include as widely as global consumer culture positioning (GCCP, Alden et al., 1999), national culture and persuasion (Aaker 2000) and influences of national culture on word of mouth (WOM) (Money, Gilly and Graham, 1998). Meanwhile, the study of national culture in NPD is widely investigated from different angles by researchers (Griffith, Yalcinkaya and Rubera, 2014; Wu, Liu and Zhang, 2017; Eisend, Evanschitzky and Gilliland, 2016; Engelen, Brettel and Wiest, 2012; Garrett, Buisson and Yap, 2006; Chang, Hung and Lin, 2014). For instance, researchers indicate that national culture influences NPD (Nakata and Sivakuma, 1996; Rhyne et al., 2002; Garrett, 2006) and moderates the relationship between organizational culture and new product performance (Eisend, Evanschitzky \& Gilliland, 2016), national culture moderates the relationship between time lag and performance of new experience products and between previous entered countries and performance of new experience products (Griffith, Yalcinkaya \& Rubera, 2014). The individualism dimension of national culture positively moderates the relationship between cross-functional integration and new product success (Engelen, Brettel \& Wiest, 2012). Further, as Money, Gilly and Graham (1998) suggest, culture affects buyers' behavior and thus, product success.

However, scant research has examined the influence of national culture on consumer-perceived NPC at the individual customer level. Through testing contagion theory, this research focuses on national cultural traits and seeks to answer two specific questions: (1) Does culture value influence NPC? and (2) How does national culture influence NPC? This study extends and supplements extant research by evaluating how national culture variables differently influence both consumer-perceived NPC and consumers' adoption behavior of creative new products. By assessing both national culture and customer PI, our findings enable academic scholars and industrial managers to understand why and how national culture affects consumers' NPC consumption and how to utilize different cultures as a strategy to achieve marketing objectives. The subsequent sections illustrate the theoretical framework, propositions, discussions, implications and future study.

\section{THEORETICAL FOUNDATIN AND PROPOSITIONS DEVELOPMENT}

\section{New Product Creativity}

New product creativity is documented diversely in literature. Some researchers emphasize the two elements of novelty and usefulness when understanding NPC (Nakata et al. 2018; Chuang, Morgan and Robson, 2014; Moreau and Dahl, 2005; Amabile, 1988, 1996a; Woodman et al. 1993; Im and Workman, 2004, Im, Montoya \& Workman, 2013). Others emphasize the aspect of value creation to customers 
(Titus 2007), problem solving in a new way (Dayan, Ozer and Almazrouei, 2017; Moorman and Miner, 1997; Andrews and Smith, 1996; Moorman, 1995), creativity as an achievement (Fillis and McAuley, 2000) or culture rooted art-making and aesthetics (Elliot and Nakata, 2013). However, major NPC discussions are based on managers' perspective and at the project or organization level, in which NPC is sometimes are confounded with new product innovation (NPI).

To date, very little research has addressed NPC from consumers' perspective, and no consensus exists on the definition of consumer-perceived NPC. Horn and Salvendy (2006, 2009) conceptualized six dimensions of NPC, but this definition is restricted to visual perspective of product functionality and limited solely to consumer products, which may limit our understanding of consumer-perceived NPC. Later, a broader and clearer NPC conceptualization based on general products is validated through empirical studies at individual consumer level, and consumer-perceived NPC is defined as "the degree to which new products are meaningful and are uniquely different from competitor products in terms of consumers' perceptions in a way that the meaningful and unique attributes could be appreciated by consumers" (Xu, 2009; Xu and Peterson, 2013, pp.18-19).

The current study adopts Xu and Peterson's (2013) broader concept for three reasons. First, this study investigates the acceptance of creative new products from consumers' perspective rather than from managers' perspective. Second, in line with previous research (Chandrasekaran and Tellis, 2008), this study investigates universal, creative new products rather than focusing only on consumer products or visual functionality of consumer products. Third, this study is based on the individual consumer level and is different from research at the aggregate consumer level. As a result, we explore NPC across the copresence of three decomposed dimensions in this study (Xu and Peterson, 2013, pp.18-19): (1) consumerperceived NPC meaningfulness, which refers to "the degree to which the new attributes imbedded in a new product are useful and are appropriate to consumers as perceived by them"; (2) Consumer-perceived $N P C$ novelty, which refers to "the extent to which consumers perceived new products uniquely differ from competitive products"; and (3) consumer-perceived NPC communicableness, which refers to "the extent to which new product novelty and meaningfulness are understandable, discernible and appreciated by customers".

\section{New Product Creativity and Purchase Intention}

Intentions result in behaviors (Ajzen, 1991), and thus PI could be viewed as a proxy for product adoption. Customer purchase intentions are affected by physical resources necessary for purchase and estimated practical benefits from a product and considerations about "how the purchase may help achieve social goals, such as self-presentation and conformance to social norms" (Baker, Donthu and Kumar, 2016, p.226; Ajzen 1991). Although limited, the relationship between NPC and PI is investigated by several scholars. For example, by applying the NPC definition of managers' view, Im, Bhat and Lee (2015) verified that utilitarian- value and hedonic-value mediate the relationships between product novelty and consumers' attitudes to creative products and between product meaningfulness and consumers' attitudes to creative products. Meanwhile, applying the NPC definition of consumers' view, researchers have demonstrated that consumers' affect contributes to consumers' willingness to purchase creative consumer products (Horn and Salvendy, 2009), and NPC meaningfulness is positively related to consumers' purchase intention, but NPC novelty and NPC communicableness mediate this relationship (Xu, 2009). Consistent with Baker, Donthu and Kumar (2016), "purchase intention" in this study is defined as the degree of motivation and willingness to eventually buy the creative new product.

\section{Contagion Theory}

Consumers' behavioral consequences may also be affected differently by people within different countries having diverse cultural values. As social contagion theory suggests, individual attitudes and behaviors are influenced by other people in their social network (Le Bon, 2018). That is, the adoption of ideas, innovations and behaviors are influenced through interactions of people in social networks (Rogers, 1995). 
While interpersonal contact through which innovation is transmitted is the core of contagion theory (Burt, 1987), researchers have introduced two models of contagion: cohesion contagion and structural equivalence contagion. Cohesion contagion emphasizes the socialization relationship between or among people. The more people associate with each other, the more individuals' adoptive behavior will be influenced. Structural equivalence emphasizes competition among people. The more people are similar to each other, the more intense the competition, and the faster people mimic competitors in adopting innovations to make more attractive alterations.

\section{National Culture}

Classical study of national culture can be traced to Hofstede. In his early work, he identified four national culture dimensions: uncertainty avoidance, individualism, masculine and power distance (1980, p.213) and two further dimensions: long-term orientation and indulgence (2001). This theory provides background to explain why many marketing and NPC principles from Western environments (such as the USA and UK) may not be applicable to Eastern countries (such as India and China). This theory is also widely used to support behavioral references or business advice to firms in the global market for differences in products, brands and services (Messner, 2016). As Hofstede (1983) suggested that researchers should only focus on dimensions that are directly relevant to the study, the current research will remain consistent with the most-often-used four dimensions in NPD studies (Engelen, Brettel and Wiest, 2012; Engelen, 2010; Kirkman et al., 2006; Marno et al., 2002, Taras et al., 2009): uncertainty avoidance, individualism, masculine and power distance.

Based on contagion theory, the subsequent paragraphs illustrate how different national culture backgrounds influence consumers' purchase behavior of creative new products. The construct of national culture is chosen because the way consumers perceive new product creativity depends on their cultural heritage, and no one can avoid her/his cultural background. Other moderating variables such as product category are not included in this research and are treated as control variables due to theoretical cohesion and in the interest of parsimony, which serves as a boundary condition. Our theorization should hold regardless of the product category. The conceptual framework below demonstrates the relationships, and the theoretical underpinning of the model guiding our research is based on the study of Xu (2009), wherein NPC meaningfulness is a mediating factor in the NPC-PI relationship. In this research, we aim to understand whether the mediation effect of NPC meaningfulness differs as a function of national culture. Said differently, we focus on the moderation effect of national culture on the NPC-PI relationship.

FIGURE 1

MODERATE OF NATIONAL CULTURE MODEL

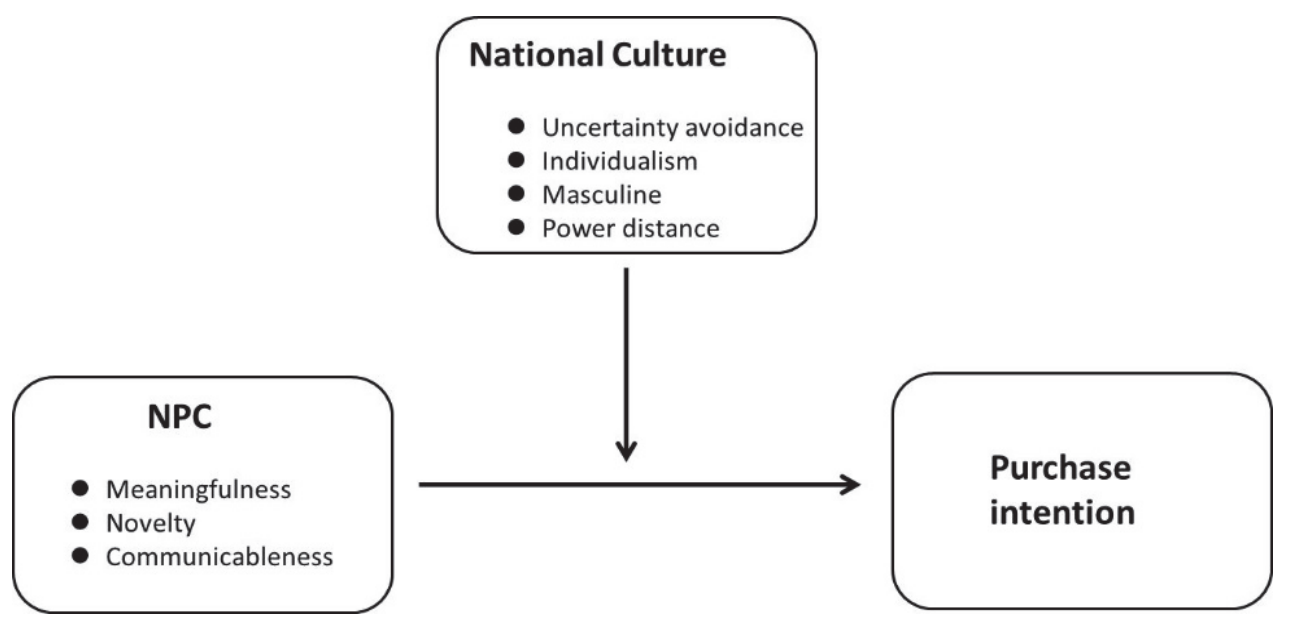


Since people in different countries have different cultural backgrounds and have been influenced by different types of social contagion models, based on the previous discussion, we propose:

Proposition 1: The influence of new product creativity (NPC) on consumer purchase intention (PI) of creative products differs across countries.

\section{Moderating Effect of Uncertainty Avoidance}

Uncertainty avoidance (UA) refers to "the extent to which a society feels threatened by uncertain and ambiguous situations" (Hofstede 1980, p.165; 2001; Hofstede, Hofstede and Minkov, 2010), It reflects how the whole society deals with unknown events in the future. A society with low UA tendencies has a high tolerance to various consequences, and people in this society feel a degree of security and show a low level of information search (Griffith, Yalcinkaya and Rubera, 2014; Nokata and Sivakumar, 1996; Van Everdingen, Fok and Stremersch, 2009). In contrast, a society with high UA has a low tolerance to risks and ambiguity, a need for clear rules and formality of life (Yeniyurt and Townsend, 2003), requires predictability and avoids ambiguity (Samaha, Beck, \& Palmatier, 2014, p. 83).

Research has illustrated that uncertainty avoidance is negatively related to (1) consumers' new product acceptance rate (Yeniyurt and Townsend, 2003), (2) companies' innovation adoption (Waarts and Evaerdingen, 2005), (3) information and communication technology diffusion (Erumban and Jong, 2006), (4) new product innovation (Rhyne et al., 2002) and (5) use of IT infrastructure (Png, Tan and Wee, 2001). Therefore, high UA may impede product diffusion and result in hesitation or rejection of creative new product adoption.

Cohesion contagion indicates UA expansion in high UA societies because "people manage uncertainty by drawing on others to define a socially acceptable interpretation of the risk" (Burt, 1987, p. 1288). When consumers notice the attitudes and behaviors of friends and social networks to uncertainty or unknown things, their perceptions may be influenced, and then the whole society may maintain a high risk-aversion attitude in a high-UA society, and vice versa in a low-UA society. Therefore, a high-UA culture, with the contagion effect of cohesion, drives individuals in that society to avoid novel or unproven new products.

Uncertainty occurs when people are not confident about the environment and feel unable to predict the likelihood of event change or lack understanding of how the environment will affect them or organizations (Messner, 2016; Milliken, 1987). Meanwhile, a new product is unknown and its performance is more ambiguous than an established product (Griffith, Yalcinkaya and Rubera, 2014; Dwyer, Mesak and Hsu, 2005). Therefore, new products cause higher uncertainty than do existing products. Members in high-UA societies consider novel and innovative things as dangerous and suspicious and hence, resist them, while members in low-UA societies are more open to change and new ideas (Efrat, 2014; Broekhuizen, Giarratana, Torres, 2017). Therefore, it is reasonable to assume that consumers are less confident regarding changes in creative new products in a high-UA society and thus refrain from activities involving creative products. Consequently, consumers often have lower PI in highthan in low-UA societies if a product is very novel. Empirical study has revealed that NPC meaningfulness positively mediates the NPC novelty-PI relationship (Xu, 2009). Therefore, UA negatively moderates the indirect relationship between NPC novelty and consumers' new product acceptance through NPC meaningfulness. Thus, we propose:

Proposition 2a: Uncertainty avoidance in a given culture moderates the strength of the positive relationship between NPC novelty and PI through NPC meaningfulness, such that the indirect relationship is weaker in a high than low uncertainty avoidance society.

By the same token, consumers are less confident in estimating returns from changes in creative new products and search for product-related information more often in high-UA societies. Consumers' requirements for detectable benefits and usefulness are correspondingly stronger in high-UA cultures, as are their requirements regarding the level of ease in appreciating these meaningful attributes or product functionalities. In other words, consumers in high-UA cultures are highly risk-averse for gain (Hardisty 
and Pfeffer, 2017; Kahneman and Tversky, 1979) and do not want to take undue risks when buying new creative products unless product benefits that are clearly larger than costs or benefits can be comprehended apparently. Conversely, consumers in low-UA cultures have fewer such concerns and are more willing to seek creative new products. Meanwhile, research indicates that for individuals, engaging in uncertainty control led to adaptive outcomes (Witte, 1993; Meulenaer, Pelsmacker and Dens, 2015). As a result, if consumers in high-UA societies discover that a new product is highly useful, or its benefits and implications are easily detected or appreciated, then they will feel more powerful in uncertainty control and more confident in calculations of gains and loss, and thus consumers' acceptance rate for creative new products will be enhanced accordingly. Nevertheless, the weight ratio of a meaningful and easy-tounderstand product is smaller for low UA consumers to purchase creative new products. Research has indicated that NPC meaningfulness is positively related to PI and indirectly mediates the NPC communicableness-PI relationship (Xu, 2009). Based on the above discussion, we thus expect the NPC meaningfulness-PI relationship is stronger in high-UA societies, and the indirect relationship between NPC communicableness and PI through NPC meaningfulness is stronger in high-UA societies. Therefore, the following propositions are offered:

Proposition 2b: Uncertainty avoidance in a given culture moderates the strength of the positive relationship between NPC meaningfulness and PI, such that the positive relationship is stronger in a high than low uncertainty avoidance society.

Proposition 2c: Uncertainty avoidance in a given culture moderates the strength of the positive relationship between NPC communicableness and PI through NPC meaningfulness, such that the indirect relationship is stronger in a high than low uncertainty avoidance society.

\section{Moderating Effect of Individualism}

Individualism refers to "the relationship between the individual and the collectivity which prevails in a given society" (Hofstede, 1980, p.213; 2001; Hofstede, Hofstede and Minkov, 2010). Individualism implies a loose social framework in which individuals focus on themselves and their immediate family and the pursuit of personal initiatives, self-achievement and control of their own fate, and emphasize confidence and competitiveness (Saad, Cleveland and Ho, 2015; Hofstede, 2001). Conversely, collectivism implies a tight social framework in which people concentrate on extended family and seek group goals, social usefulness and being cared for by group members. An individual's self-conceptions flow from social identity, and "his/her behaviors are determined by the thoughts, feelings and action of others", emphasizing group-decisions and acceptance of authority (Saad, Cleveland and Ho, 2015; Hofstede, 2001).

The impact of individualism on NPD is examined extensively, with potential insights. For instance, researchers report that a country's level of individualism is positively related to NPI (Rhyen et al., 2002), new product adoption (Yeniyurt and Townsend, 2003; Erumban and Jong, 2006), new product development (Nokata and Sivakumar, 1996), and country inventiveness (Shane, 1993). It seems that high individualism encourages people to enjoy creative things.

Individuals pursue independence, competition and pleasure in individualistic countries (Hofstede, 1983, 2001) and thus, structural equivalence cohesion is assumed to exist in an individualistic culture. People compete with each other and are more willing to imitate competitors' behaviors to stand out from all competitors, which includes imitating the adoption of new creative products. The more intense the competition, the faster the mimicking behavior. At the same time, people in individualistic cultures display high levels of overconfidence due to an increased self-esteem mechanism (Heine et al., 1999, p. 338; Cheon and Lee, 2018) and are self-oriented and freer to make their own choices (Saad, Cleveland and Ho, 2015). Individualists value personal initiative and uniqueness (Hofstede, 2001), which drives consumers to quickly apply novel products to their everyday life. Conversely, collectivists attenuate their confidence, and their choices are carried over into group decisions, which slows down the adoption of novel products (Saad, Cleveland and Ho, 2015). Therefore, we propose: 
Proposition 3a: Individualism in a given culture moderates the strength of the positive relationship between NPC novelty and PI through NPC meaningfulness, such that the indirect relationship is stronger in an individualistic than collectivistic society.

In collectivist countries, individuals are interdependent, cooperative and less competitive, and people attend to family security and social hierarchies (Triandis, 1990; Zhang 1995). The cohesion influence can be predicated in a collectivistic culture. These individuals are influenced by each other through detected attitudes and behaviors of others. Product advertising in collectivistic countries utilizes indirect and implicit messages that emphasize socialization to cultivate consumer engagement and relationship and employ appeals to emotion and harmony-seeking to build a seller-buyer relationship (Kitirattarkarn, Araujo and Neijens, 2019; Pae, Samiee and Tai, 2013). Consumers from collectivistic cultures tend to rely heavily on personal networks (e.g., close friends, family) for brand-related information and social support, while individualistic consumers prefer to consult a wider range of information sources (Chu and Choi, 2011; Tsai and Men, 2014; Kitirattarkarn Araujo and Neijens, 2019) and product advertising tends to be informative, relying on facts and the unique benefit of the advertised product (Pae, Samiee, and Tai, 2013). Therefore, the analytical approach is different when making a purchase decision, and NPC benefits are more important for individualistic than collectivistic consumers for this decision. Therefore, we propose:

Proposition 3b: Individualism in a given culture moderates the strength of the positive relationship between NPC meaningfulness and PI, such that the relationship is stronger in an individualistic than collectivistic society.

Cross-cultural research illustrates that marketing communication varies in individualistic and collectivistic cultures. For instance, people tend to have implicit, abstract and high-context communication in collectivistic countries. Conversely, in individualistic culture, people have explicit, straightforward and low-context communication (Hall, 1977; Hofstede, 2001; Kitirattarkarn, Araujo and Neijens, 2019). Collectivistic buyers use more WOM referral sources (Money, Gilly and Graham, 1998) and interpersonal communication to detect product usefulness and handle risks. However, in individualistic countries, consumers are autonomous and more willing to assess product advantages and disadvantages by themselves. Individualists believe they have unique personal attributes such as traits, abilities, and motives that could largely determine their unique autonomous behaviors (Rupp et al., 2018; Kim, Wang, Kondo, \& Kim, 2007; Sampson, 1988, 1989). Therefore, direct information for easy understanding of product benefits is more important for consumers in individualistic cultures for purchase decisions; for these consumers, new product benefits and novel attributes must be easy to appreciate. To summarize, we propose:

Proposition 3c: Individualism in a given culture moderates the strength of the positive relationship between NPC communicableness and PI through NPC meaningfulness, such that the indirect relationship is stronger in an individualistic than collectivistic society.

\section{Moderating Effect of Masculinity}

Masculinity is "the extent to which the dominant value in the society is 'masculine' with the features of assertive and pursuing money and etc." (Hofseted, 1980, pp.262-77). Research indicates that masculinity or femininity is a taken-for-granted hegemonic standard in a given culture, and it informs people's actions and others' interpretation of them (Spence \& Helmreich, 1978; Avery, 2012). Masculine society emphasizes values related to success, acquisition of money (Hofseted, 2001), competitiveness, ambition, and domination (Neale, Robbie and Brett, 2016), while feminine society focuses on value from quality of life, helping others (Hofseted, 2001), nurturing, emotional attachment, and affiliation (Neale, Robbie and Brett, 2016). Structural equivalence contagion is assumed to exist in masculine culture, and a 
high level of masculinity is maintained accordingly, because people in masculine culture want to demonstrate success and engage in competition and thus, imitation happens among competitors.

Research indicates that consumption behavior is gendered (Avery, 2012; Fischer \& Arnould, 1990; Sherry, Kozinets, Duhachek, et al., 2004; Wallendorf \& Arnould, 1991). Masculinity is positively related to new product adoption (Yeniyurt and Townsend ,2003) and consumers' innovativeness (Steenkamp et al., 1999). Masculinity is viewed as "a set of bodily influenced but socially constructed behaviors and attitudes that are enacted either voluntarily or subconsciously" (Littlefield, 2010). Rogers (1983) indicated that people enjoy demonstrating their success and achievement through owning the latest and most novel possession, to reflect social status and wealth. Collectively, people in masculine countries purchase novel products faster than in feminine countries. Hence, masculinity may positively impact consumer attitudes regarding NPC novelty.

Proposition 4a: Masculinity in a given culture moderates the strength of the positive relationship between NPC novelty and PI through NPC meaningfulness, such that the indirect relationship is stronger in a masculine than feminine society.

Consumers in masculine societies do not tend to other people in decisions and prefer to detect product benefits independently (Griffith, Yalcinkaya and Rubera, 2014; Roth, 1995); thus benefits are important in their decisions. By the same token, ease in understanding product values is not critical for consumers' purchase decisions in a masculine society. The following propositions are proposed based on the discussion:

Proposition 4b: Masculinity in a given culture moderates the strength of the positive relationship between NPC meaningfulness and PI, such that the positive relationship is stronger in a masculine than feminine society.

Proposition 4c: Masculinity in a given culture moderates the strength of the indirect relationship between NPC communicableness and PI through NPC meaningfulness, such that the indirect relationship is stronger in a masculine than feminine society.

\section{Moderating Effect of Power Distance}

Power distance (PD) refers to "the extent to which a society accepts the fact that power is distributed unequally" (Hofseted, 1980, pp.262-77). Societies with high PD are more autocratic and more easily accept power and wealth distances. Such societies are characterized by centralized decisions, formal rules, and information constrained by hierarchy (Waarts and Everdingen, 2005). Norms in high PD cultures legitimize the decision-making power of those in high positions, and people in these cultures prefer hierarchy (Paharia and Swaminathan, 2019). In contrast, societies with low-PD focus on equality of power and wealth (Hofstede, 1980, pp.104). Norms in low PD cultures attenuate differences of decisionmaking power among people, who prefer egalitarianism (Paharia and Swaminathan, 2019).

A structural equivalence contagion model is assumed to exist in high PD countries, given the societies' preference to chase a higher level of power and privilege; thus, competition is more intense in high-PD countries. The more competition, the more mimicking behavior (Le Bon, 2018), therefore, mimicking behavior is more popular in high-PD countries at a macro level.

Meanwhile, people in high PD countries need structure and order, which drives them to be dedicated to specific roles and bringing order to the hierarchical society in social interactions and nonsocial domains (Lalwani and Forcum, 2016; Carl, Javidan, and Gupta, 2004; Hofstede, 2001; Su et al., 1999; Thompson et al., 2001). Furthermore, one study finds that individuals high in need for structure do not want to change and are more likely to engage in stereotyping (Lalwani and Forcum, 2016). At the same time, research has indicated that high PD is relevant to conservatism and maintaining the status quo, and consumers are less innovative and less open to new ideas and new products (Steenkamp, 2001; Yeniyurt and Townsend, 2003; Yaveroglu and Donthu, 2002). Conversely, low PD contributes to information 
sharing and psychological safety, which in turn contributes to team creativity (Hu, Erdogan, Jian, Bauer and Liu, 2017). Researchers have demonstrated that PD is negatively related to national-level innovation (Rinne, Steel and Fairweather, 2012; Daneils and Greguras, 2014), and innovative climates are more likely to develop in low-PD cultures, because individuals with different levels of status are more likely to work together, and different opinions by subordinates are more likely to be voiced and lead to more creativity and innovation in low-PD cultures (Van der Vegt, Van de Vliert and Huang, 2005; Daneils and Greguras, 2014). As a result, people in high-PD societies are slow to adopt novel products due to stereotyping habits, maintaining the status quo, and people's high imitating interaction behavior based on structural equivalence contagion. Contrastingly, people in low-PD societies are quick to adopt novel products due to the open-minded and innovative climate. Therefore, the indirect effect of product novelty on consumers' PI through product meaningfulness is lower in high-PD countries than in low-PD countries. In line with our discussion above, we propose:

Proposition 5a: Power distance in a given culture moderates the strength of the positive relationship between NPC novelty and PI through NPC meaningfulness, such that the indirect relationship is weaker in a high than low power distance society.

Inequality is expected and accepted in high-PD countries (Winterich, Gangwar and Grewal, 2018; Winterich and Zhang, 2014), and these consumers consider people higher up in the hierarchy as superior (Brockerner et al., 2001; Paharia and Swaminathan, 2019). As such, high-PD consumers may value decisions from those high in the hierarchy; they are more willing to follow the decision-maker in a high level of hierarchy and less likely to make their own decisions. Meanwhile, research (Laufer, Carrett and Ning, 2018; Jung and Kellaris, 2006; Pornpitakpan and Francis, 2000) indicates that customers' trust is enhanced if messages are delivered by authorities rather than regular spokespeople, which improves customers' PI in high-PD culture compared to low-PD cultures. Consumers like to follow authority in high-PD cultures. High PD influences purchase intention (Laufer, Carrett and Ning, 2018). In contrast, low-PD consumers do not consider those in high positions of hierarchy as superior; they value selfjudgments and their own ideas as important (Brockerner et al., 2001; Paharia and Swaminathan, 2019). Low-PD consumers do not assign credibility to authority and do not look for direction or guidance from people with power. Instead, they search for facts and evidence and apply reasoning for decision-making (Winterich, Gangwar and Grewal, 2018; Hofstede, 1991). Therefore, high-PD consumers are more likely to follow superiors or people in a high level of hierarchy and less likely to search for facts and product information for a purchase decision, whereas, low PD consumers are more likely to search for facts and product features for a purchase decision. Further, people in high-PD countries are reluctant to pass over social classes to associate with each other and share product information due to hierarchy. Conversely, low-power-distance consumers have more opportunities to interact with different people and seek WOM information for product decisions due to the features of an egalitarian society. Consequently, identified product usefulness is more important to people in high-PD societies than it is in low-PD societies. Therefore, meaningful products are more important for purchase decisions for consumers in low-PD societies. Based on the previous discussion, we propose the following:

Proposition 5b: Power distance in a given culture moderates the strength of the positive relationship between NPC meaningfulness and PI, such that the positive relationship is weaker in a high than low power distance society.

High-power individuals are agentic-oriented and place more importance on themselves in decision making (Rucker et al., 2012). Therefore, high-PD individuals focus on themselves more than on product features. Conversely, low-PD consumers often depend on others to convert resources and attend to others' preferences (Rucker et al., 2011; Han, Lalwani and Duhackek, 2017). Therefore, people in low-PD societies are more dependent on WOM or communication to understand new product benefits. As such, appreciation of product usage without difficulty (i.e., NPC communicableness) is vital to consumers in 
low-PD countries. If these consumers can easily see the advantages and positive attributes of new creative products, then their purchase intention will be larger than if they cannot easily see the useful product attributes.

Proposition 5c: Power distance in a given culture moderates the strength of the positive relationship between NPC communicableness and PI through NPC meaningfulness, such that the indirect relationship is weaker in a high than low power distance society.

\section{DISCUSSION}

In the marketing field, literature emerged on NPD focuses on innovation and creativity, but such research is rare in culture-variance context. Cross-cultural study of NPC from the consumers' perspective is lacking. To address this lacuna, the author developed a framework to advance NPC research and bridge the gap.

This study is motived by two questions: (1) Does national culture influence purchase behavior in NPC? (2) How does national culture influence purchase behavior in NPC? The theoretical model developed in this research is grounded on the well-accepted theory of national culture (Hofstede, 1980) and contagion theory (Le Bon, 2018; 1896; Burt, 1987) and predicts new marketing phenomena. Specifically, this national culture model has a foundation in contagion theory, indicating that crowd effects individuals' behavior in a society. As such, individuals' consumption behavior toward new creative products will be shaped by the crowd. Depending on different cultural environments in different countries, crowd influence will be different. The higher the level of UA, individualism and masculinity, or the lower the level of PD in a culture, the stronger the impact of the national culture on consumers' purchase behavior toward creative new products in terms of meaningful products and easy-to-understand products. The lower the levels of UA and PD, or the higher level of individualism and masculinity in a given culture, the stronger the influence of national culture on individuals' consumption behavior toward creative new products in terms of novel products.

The theoretical model and set of propositional statements that can be developed for empirical testing have implications for theory and practice in specific ways.

\section{Theoretical Contribution}

This theoretical model provides three main contributions to the literature. First, it contributes to international marketing research and expands international marketing theory foundations. Friedman (2007) indicated that the world is flat and products span country boundaries, but uncertainty originates from the unpredictable difference between home and host environment (Gooris \& Peeters, 2014). As such, traditional marketing theories based on clan culture cannot be applied to the international market. Different types of culture have experienced different success, but national culture is rarely used in new product development (Evanschitzky et al., 2012). By considering the variables of national culture, this set of propositions offers opportunities to investigate the dynamic linkages and relationships between NPC constructs and consumers' purchase intention/behavior in international markets across different countries, which fills an important knowledge gap. This model provides theories appropriate to different countries with diverse cultural backgrounds. It advances international marketing and the influence of national culture on international markets. For instance, we specify how culture moderates the direct effects of NPC on purchase intention and how each dimension of national culture influences consumption in the international market.

The second major contribution is that this study advances the new product research stream and identifies the gap in cross-cultural theory in NPC research. Within marketing, extant culture-related NPC research has discussed how to improve product performance or product development strategies with a focus on managers' or organizational perspectives (Nakata, 2018; Elliot and Nakata, 2013). Limited

research has focused on an individual consumers' perspective. This study has focused on NPC not only from an individual consumer's perspective but also ien the context of national culture at aggregate level, 
extending the literature on general NPC studies from a managers' perspective (Im, Montorya and Workman Jr., 2013; Kim, Im and Slater, 2013; Im, Bhat and Lee, 2015) and from the perspective of visual functionality of consumer products (Horn and Salvendy, 2006; 2009).

Third, this research contributes to consumer research, since it focuses on the interface of NPD and consumer behavior in different countries. It reveals that different consumer behaviors result from a complicated decision-making process for new products. The study also complements national culture theories. Prior NPC research focuses on two culture forms linked to economic development: traditionsecular and survival-self-expression (Nakata et al., 2018). By employing Hofstede's four widely used dimensions and linking them to a broadened NPC concept to include general products, this study extends national culture study to the domain of NPC research and sheds light on when and why national culture could be considered as a marketing strategy.

Last but not least, this study contributes to inter-discipline research. To illustrate the utility of this conceptual framework, this study is novel in connecting NPD research with sociology research and testing the well-known contagion theory in marketing. It finds that different cultural backgrounds impact consumers' purchase intention/behavior toward new products differently because people in the same country share similar social norms and behaviors.

\section{Managerial Implications}

This research offers managerial insights and indicates the importance of national culture on the expansion of creative new products internationally. First, it benefits companies' strategic orientations. Since many companies have branches overseas, and new products such as Apple and Samsung products are sold internationally, customized promotion strategies are essential to meet local consumers' needs and satisfaction to change local consumers' consumption behavior. For instance, this research indicates that the impact of NPC meaningfulness and communicableness on consumers' purchase intention is higher in high UA countries than in low-UA countries. When launching products in high-UA counties such as China and India, managers could emphasize and demonstrate the usage or functional aspects of new products to consumers in advertisements or promotions. For example, how meaningful is the product to consumers? How will it change or benefit consumers' everyday life? As such, advertisements and promotions will be more persuasive to consumers and thus, consumers are more easily drawn to buy the new products. Managers also need to make sure new products are easily understood by consumers in high-UA countries when describing their functions or features in advertisements or promotions because the impact of NPC communicableness (easily understood) will be stronger in high risk-aversion countries.

Similarly, advertising and promotion strategies should emphasize products' novel aspects in high individualistic countries because consumers are more willing to purchase novel products to demonstrate social status. By the same token, advertising and promotion strategies should be different in countries with higher PD, individualism and masculinity than in those lower in these dimensions.

Cultural distance between home and host countries is the origin of differences in operating processes, routines and knowledge bases among multinational firms (Gooris \& Peeters, 2014; Anderson \& Gatignon, 1986). By considering culture variance, stakeholders can customize different organizational strategies to run overseas business successfully. Managers can target consumers in the international market more precisely and apply different marketing strategies for consumers in different cultures. The strategy consummation benefit can be applied to different aspects of marketing, customer loyalty, brand image, and recognition and reputations, and thus improve product success and sales. This research improves managers' awareness regarding how to use national culture to improve new product success in the international market.

\section{DIRECTIONS FOR FUTURE RESEARCH}

There are several research opportunities for the future. The first is that researchers can continue to do empirical study by collecting data from Eastern and Western countries with different national and cultural backgrounds. Secondly, a test could be conducted to check whether the impact of national culture can be 
replicated in business-related aspects other than purchase intention, for instance, in brand strategies. Third, researchers could link this theory model to additional moderators or mediators to augment this framework in NPC-related consumer purchase behavior. Finally, researchers could investigate whether national culture will influence consumers' online and offline purchase behavior for imported products versus local products differently. We also leave the product category to future research in terms of national culture and NPC relationship.

\section{REFERENCES}

Alden, D.L., Steenkamp, J.B., \& Batra, R. (1999). Brand positioning through advertising in Asia, North America, and Europe: the role of global consumer culture. Journal of Marketing, 63(1), 75-87.

Andéhn, M., Fredrik, N., \& Nilsson, M. E. (2016). Facets of country image and brand equity: revisiting the role of product categories in country-of-origin effect research. Journal of Consumer Behaviour, 15(3).

Ajzen, I. (1991). The theory of planned behavior. Organizational Behavior and Human Decision Processes, 50(2), 179-211.

Avery, J. (2012). Defending the markers of masculinity: consumer resistance to brand gender-bending. Intern. Journal of Research in Marketing, 29, 322-336.

Baker, A.M., Donthu, N., \& Kumar, V. (2016). Investigating how word-of-mouth conversations about brands influence purchase and retransmission intentions. Journal of Marketing Research, 53(2).

Bailey, N., \& S. Li. (2015). Cross-national distance and FDI: The moderating role of host country local demand. Journal of International Management, 21(4).

Broekhuizen, T.L.J., Giarratana, M.S., \& Torres, A. (2017). Uncertainty avoidance and the explorationexploitation trade-off. European Journal of Marketing, 51(11/12).

Brockner, J., Ackerman, G., Greenberg, J., Gelfand, M.J., Francesco, A.M., \& Chen, Z.X. (2001). Culture and procedural justice: the influence of power distance on reactions to voice. Journal of Experimental Social Psychology, 37(4).

Burt, R.S. (1987) Social contagion and innovation, cohesion versus structural equivalence. American Journal of Sociology, 92, 1287-1335.

Carl, D., Javidan, M., \& Gupta, V. (2004). "Power Distance" in Culture, Leadership, and Organizations: The Globe Study of 62 Societies, ed. Robert J. House, Paul J. Hanges, Mansour Javidan, Peter W. Dorfman, and Vipin Gupta, Thousand Oaks, CA: Sage, 513-59.

Chang, J.J., Hung, K.P., \& Lin, M.J.J. (2014). Knowledge creation and new product performance: the role of creativity. $R \& D$ Management, $44(2)$.

Chandrasekaran, D., \& Tellis, G.J. (2008). Global takeoff of new products: culture, wealth, or vanishing differences? Marketing Science, 27(5).

Cheon, Y.H., \& Lee, K.H. (2018). Maxing out globally: individualism, investor attention, and the cross section of expected stock returns. Management Science, 64.

Chuang, F. M., Morgan, R.E., \& Robson, M.J. (2014). Customer and competitor insights, new product development competence, and new product creativity: differential, integrative, and substitution effects. Journal of Product Innovation Management, 32(2).

Cui, A., Walsh, M. F., \& Zou, J.J. (2014). The importance of strategic fit between host-home country similarity and exploration exploitation strategies on small and medium-sized enterprises' performance: A contingency perspective. Journal of International Marketing, 22(4), 67-85

Daniels, M.A., \& Greguras, G.J. (2014). Exploring the nature of power distance: implications for microand macro-level theories, processes, and outcomes. Journal of Management, 40(5).

Dayan, M., Ozer, M., \& Almazrouei, H. (2017). The role of functional and demographic diversity on new product creativity and the moderating impact of project uncertainty. Industrial Marketing Management, 61, 144-154. 
De Meulenaer, S., De Pelsmacker, P., \& Dens, N. (2015). Have no fear: how individuals differing in uncertainty avoidance, anxiety, and chance belief process health risk messages. Journal of Advertising, 44(2).

Dwyer, S, Mesak, H., \& Hsu, M. (2005). An exploratory examination of the influence of national culture on cross-national product diffusion. Journal of International Marketing, 1(2), 1-27.

Efrat, K. (2014). The direct and indirect impact of culture on innovation. Technovation, 34(1), 12-20.

Eisend, M., Evanschitzky, H., \& Gilliland, D.I. (2016). The influence of organizational and national culture on new product performance. Journal of Product Innovation Management, 33(3).

Eliot, E.A., \& Nakata, C. (2013). Cross-cultural creativity: conceptualization and propositions for global new product development. Journal of Innovation Management, 30(S1), 110-125.

Engelen, A., Brettel, M., \& Wiest, G. (2012). Cross-functional integration and new product performancethe impact of national and corporate culture. Journal of International Management, 18, 52-65.

Engelen, A. (2010). Entrepreneurial orientation as a function of national cultural variations in two countries. Journal of International Management, 4, 354-368.

Fischer, E., \& Arnould, S.J. (1990). More than a labor of love: gender roles and Christmas gift shopping. Journal of Consumer Research, 17(3), 333-345.

Friedman, T. (2007). The World is Flat. New York, NY: Farrar, Straus and Giroux.

Gao, H., Tate, M., Zhang, H., Chen, S., \& Liang, B. (2018). Social media ties strategy in international branding: an application of resource-based theory. Journal of International Marketing, 26(3).

Gooris, J., \& Peeters, C. (2014). Home-host country distance in offshore governance choices. Journal of International Management, 20(1).

Griffith, D.A., Yalcinkaya, G., \& Rubera, G. (2014). Country-level performance of new experience products in a global rollout: the moderating effects of economic wealth and national culture. Journal of International Marketing, 22(4), 1-20.

Hall, E. T. (1977). Beyond Culture. Garden City, NY: Anchor Press.

Han, D., Lalwani, A., Ashok, K., \& Duhachek, A. (2017). Power distance belief, power, and charitable giving. Journal of Consumer Research, 44(1).

Hardisty, D.J., \& Pfeffer, J. (2017). Intertemporal uncertainty avoidance: when the future is uncertain, people prefer the present, and when the present is uncertain, people prefer the future. Management Science, 63(2).

Heine S.J., Lehman, D.R., Markus, H.R., Kitayama, S. (1999). Is there a universal need for positive selfregard? Psych. Rev., 106(4), 766-794.

Hofstede, G. (1980). Culture's consequences-international differences in work-related values. SAGE Publications, Inc., Newbury Park, 132-135.

Hofstede, G. (1983). Dimensions of national culture in fifty countries and three regions, In Expiscations in Cross-Cultural Psychology, J.B. Deregowksi, S. Dziurawiec, and R.C. Annis, eds. Lisse, the Netherlands: Swets \& Zeitlinger, 335-55.

Hofstede, G. (1991). Cultures and organizations: software of the mind. London: McGraw-Hill.

Hofstede, G. (2001). Culture's consequences: comparing values, behaviors, institutions, and organizations across nations. Thousand Oaks, CA: Sage Publications.

Hofstede, G., Hofstede, G.J., \& Minkov, M. (2010). Cultures and organizations: software of the mind. London, U.K.: McGraw-Hill.

Horn, D., \& Salvendy, G. (2009). Measuring consumer perception of product creativity: impact on satisfaction and purchasability. Human Factors and Ergonomics in Manufacturing \& Service Industries, 19(3).

Hu, J., Berrin, E., Jiang, K., Bauer, T. N., \& Liu, S. (2018). Leader humility and team creativity: the role of team information sharing, psychological safety, and power distance. Journal of Applied Psychology, 103(3).

Im, S., \& Workman, J. (2004). The impact of creativity on new product success. Journal of Marketing, $68(2), 114-32$. 
Im, S., Bhat, S., \& Lee, Y. (2015). Consumer perceptions of product creativity, coolness, value and attitude. Journal of Business Research, 68(1).

Im, S., Montoya, M.M., \& Workman, J. (2013). Antecedents and Consequences of Creativity in Product Innovation Teams. Journal of Product Innovation Management, 30(1), 170-185.

Jung, J.M., \& Kellaris, J.J. (2006). Responsiveness to authority appeals among young French and American consumers. Journal of Business Research, 59, 735-744.

Kahneman, D., \& Tversky, A. (1979) Prospect theory: An analysis of decision under risk. Econometrica, 47(2), 263-291.

Kim, T-Y., \& Leung, K. (2007). Forming and reacting to overall fairness: a cross-cultural comparison. Organizational Behavior and Human Decision Processes, 104,83-95.

Kirkman, B.L., Lowe, K.B., \& Gibson, C.B. (2006). A quarter century of culture's consequences: a review of empirical research incorporating Hofstede's cultural values framework. J. Int. Bus. Stud., 37, 285-320.

Kitirattarkarn, G.P., Araujo, T., \& Neijens, P. (2019). Challenging traditional culture? How personal and national collectivism-individualism moderates the effects of content characteristics and social relationships on consumer engagement with brand-related user-generated content. Journal of Advertising, 48(2).

Kozlenkova, I.V., Samaha, S.A., \& Palmatier, R.W. (2014). Resource-based theory in marketing. Journal of the Academy of Marketing Science, 42(1).

Lalwani, A.K., \& Forcum, L. (2016). Does a dollar get you a dollar's worth of merchandise? The impact of power distance belief on price-quality judgments. Journal of Consumer Research, 43(2).

Laufer, D., Garrett, T. C., \& Ning, B. (2018). The moderating role of power distance on the reaction of consumers to the CEO as a spokesperson during a product harm crisis: insights from China and South Korea. Journal of International Management, 24(3).

Le Bon, G. (1896). The Crowd: A Study of the Popular Mind. London: Ernest Benn.

Le Bon, G. (2018). The crowd: a study of popular mind. Pretorian Books, UI. Hristo Samsarow.

Lee, K.B., \&Wong, V. (2012). Organizational coordination, development proficiency, and on-time completion of development and international rollout: a contingency analysis of external environments. Journal of Business Research, 65, 389-401.

Littlefield, J. (2010). Men on the hunt: ecofeminist insights into masculinity. Marketing Theory, 10(1), 97-117.

Marino, L., Strandholm, K., Steensma, K. \& Weaver, M. (2002). The moderating effect of national culture on the relationship between entrepreneurial orientation and strategic alliance portfolio extensiveness. Entrep. Theory Pract., 26(4), 145-160.

Messner, W. (2016). The misconstruction of Hofstede's uncertainty avoidance dimension: The fallacy of ecological operation without construct validity at the individual level. Journal of Global Marketing, 29(5).

Nakata, C., Rubera, G., Im, S. Pae, J.H, Lee, H.J., Onzo, N., \& Park, H. (2018). New product creativity antecedents and consequences: evidence from South Korea, Japan and China. Journal of Product Innovation Management, 35(6).

Nakata C., \& Sivakumar, K. (1996). National culture and new product development: an integrative review. Journal of Marketing, 60, 61-72.

Navarro-García, A., Arenas-Gaitán, J., \& Rondán-Cataluña, F.J. (2014). External environment and the moderating role of export market orientation. Journal of Business Research, 67, 740-745.

Neale, L., Robbie, R., \& Martin, B. (2016). Gender identity and brand incongruence: when in doubt, pursue masculinity. Journal of Strategic Marketing, 24(5), 347-359.

Pae, J. H., Samiee, S., \& Tai, S. (2002). Global advertising strategy: the moderating role of brand familiarity and execution style. International Marketing Review, 19(2), 176-89.

Paharia, N., \& Swaminathan, V. (2019). Who is wary of user design? The role of power-distance beliefs in preference for user-designed products. Journal of Marketing, 83(3).

Patti, D.M.A., Mudambi, M., Navarra, P., \& Baglieri. (2016). A tale of soil and seeds: the external environment and entrepreneurial entry. Small Business Economics, 47(4). 
Pornpitakpan, C., \& Francis, J.N. (2000). The effect of cultural differences, source expertise, and argument strength on persuasion: an experiment with Canadians and Thais. J. Int. Consum. Mark., 13, 77-101.

Rinne, T., Steel, G.D., \& Fairweather, J. (2012). Hofstede and Shane revisited: the role of power distance and individualism in national-level innovation success. Cross-Cultural Research, 46, 91-108.

Roth, M. S. (1995). The effects of culture and socio-economics on the performance of global brand image strategies. Journal of Marketing Research, 32, 163-75.

Rucker, D.D., Galinsky, A.D., \& Dubois, D. (2012). Power and consumer behavior: how power shapes who and what consumers value. Journal of Consumer Psychology, 22(3), 352-68.

Rupp, D.E., Shao, R., Skarlicki, D.P., Paddock, E.L., Kim, T-Y., \& Nadisic, T. (2018). Corporate social responsibility and employee engagement: the moderating role of CSR-specific relative autonomy and individualism. Journal of Organizational Behavior, 39(5).

Saad, G., Cleveland, M., \& Ho, L. (2015). Individualism-collectivism and the quantity versus quality dimensions of individual and group creative performance. Journal of Business Research, 68(3).

Samaha, S.A., Beck, J.T., \& Palmatier, R.W. (2014). The role of culture in international relationship marketing. Journal of Marketing, 78(5), 78-98.

Sampson, E.E. (1988). The debate on individualism: Indigenous psychologies of the individual and their role in personal and societal functioning. American Psychologist, 43,15-22.

Sampson, E.E. (1989). The challenge of social change for psychology: Globalization and psychology's theory of the person. American Psychologist, 44, 914-921.

Sherry, J. F., Jr., Kozinets, R.V., Duhachek, A., DeBerry-Spence, B., Nuttavuthisit, K., \& Storm, D. (2004). Gendered behavior in a male preserve: role playing at ESPN zone Chicago. Journal of Consumer Psychology, 14(1/2), 151-158.

Spence, J.T., \& Helmreich, R.L. (1978). Masculinity \& femininity: their psychological dimensions, correlates, and antecedents. Austin, TX: University of Texas Press.

Su, S. K., Chiu, C., Hong, Y., Leung, K., Peng, K., \& Morris, M.W. (1999). Self organization and social organization: US and Chinese constructions in the psychology of the social self, ed. Tom R. Tyler, Roderick Moreland Kramer, and Oliver P. John. New York: Psychology Press, 193-222.

Taras, V., Rowney, J., \& Steel, P. (2009). Half a century of measuring culture: review of approaches, challenges, and limitations based on the analysis of 121 instruments for quantifying culture. Journal of International Management, 25, 357-373.

Thompson, M.M., Naccarato, M.E., Parker, K.C.H., \& Moskowitz, G.B. (2001). The personal need for structure and personal fear of invalidity measures: historical perspectives, Current Applications, and Future Directions in Cognitive Social Psychology. The Princeton Symposium on the Legacy and Future of Social Cognition, ed. Gordon B. Moskowitz, New York: Psychology Press, 19-39.

Van der Vegt, G. S., Van de Vliert, E., \& Huang, X. (2005). Location-level links between diversity and innovative climate depend on national power distance. Academy of Management Journal, 48, 1171-1182.

van Everdingen, Y., Fok, D., \& Stremersch, S. (2009). Modeling global spillover of new product take-off. Journal of Marketing Research, 46, 637-52.

Wallendorf, M., \& Arnould, E. J. (1991). 'We gather together': The consumption rituals of Thanksgiving Day. Journal of Consumer Research, 18, 13-31.

Winterich, K.P., \& Zhang, Y.L. (2014). Accepting inequality deters responsibility: how power distance decreases charitable behavior. Journal of Consumer Research, 41(2).

Winterich, K.P., Gangwar, M., \& Rajdeep, G. (2018). When celebrities count: power distance beliefs and celebrity endorsements. Journal of Marketing, 82(3).

Witte, K. (1993). A theory of cognition and negative affect: Extending Gudykunst and Hammer's theory of uncertainty and anxiety reduction. International Journal of Intercultural Relations, 17(2), 197215.

Wu, L., Liu, H., \& Zhang, J. (2017). Bricolage effects on new-product development speed and creativity: the moderating role of technological turbulence. Journal of Business Research, 70, 127-135. 